\title{
26 STOP, COLLABORATE AND LISTEN: THE NETWORK FOR A VIOLENCEFREE HUTT VALLEY IS BACK WITH A BRAND NEW EDITION
}

doi:10.1136/injuryprev-2012-040590q.26

\footnotetext{
${ }^{1}$ A Seymour, ${ }^{2}$ D Robinson. ${ }^{1}$ Regional Public Health, New Zealand; ${ }^{2}$ Ahuru Mowai o te Awakairangi, Hutt Union and Community Health Service, New Zealand
}

Background Family violence is a major health, social and economic issue for all New Zealanders, costing the country around \$4-5 billion per year. Family violence targeted funding is mainly spent on secondary and tertiary prevention measures. However, we need to shift our thinking about how we deal with family violence within our communities.

Aims/Objectives/Purpose Ahuru Mowai o te Awakairangi, the Network for a Violence-Free Hutt Valley is one community building a foundation for a primary prevention approach towards family violence.

Methods Family Violence Networks have existed in the Hutt Valley since the 1990s and a formal Hutt Valley wide network was established by 2010. In 2011, the Network began work to strategically re-position itself away from secondary and tertiary prevention towards a primary prevention approach to family violence. Using a socio-ecological model as a framework for prevention, network agencies continue to work on responding to family violence at an individual and relationship level, while the Network's working group focuses on effecting change at community and societal levels.

Results/Outcomes In practice, this has included the set up of free family violence community education sessions, and lobbying which has resulted in the Network being represented on the WHO International Safe Communities Hutt Valley working group, and the Hutt Valley Governance Group comprising of the Mayors and the leaders of government and non-government agencies.

Significance/Contribution to the Field It is through such a co-ordinated approach, educating people and lobbying at a policy level, that Ahuru Mowai o Te Awakairangi can effect change in the area of family violence prevention. 